\title{
Making Ceramic Protective Coatings on Titanium Boride Base by Electric Arc Surfacing with SHS Electrodes in an Argon Atmosphere
}

\author{
A.O. Zhidovich*, A.M. Stolin, P.M. Bazhin, A.S. Konstantinov, A.P. Chizhikov \\ Merzhanov Institute of Structural Microkinetics and Materials Science of RAS, \\ 8, Academician Osipyan Str., Chernogolovka, 432142, Russia \\ * Corresponding author. Tel.: +7 49652463 46. E-mail: a10012012@ism.ac.ru
}

\begin{abstract}
SHS extruded TiB / 30 wt.\% Ti-layered long rods with a length of more than $100 \mathrm{~mm}$ and a diameter of 3 mm were made by electric arc surfacing on a titanium substrate in an argon atmosphere. Technological modes of coating deposition (electric arc current, arc speed, argon flow intensity, etc.) have been worked out by the method of electric arc surfacing. The structure and phase composition of the initial surfacing electrode and coating are investigated. It is shown that the deposited coating has a layered structure, its microstructure is represented by titanium diboride and monoboride in a matrix consisting of a solid boron in titanium solution. It was found that the structure and phase composition of the coating are predominantly identical to the structure and phase composition of the used SHS electrodes. The microhardness of the deposited electrode and coating was 1024 and $1420 \mathrm{HV}$, respectively.
\end{abstract}

\section{Keywords}

Titanium boride; protective coatings; metal-matrix composite; microstructure; SHS extrusion; electric arc surfacing.

(C) A.O. Zhidovich, A.M. Stolin, P.M. Bazhin, A.S. Konstantinov, A.P. Chizhikov, 2020

\section{Introduction}

Making protective coatings by the method of electric arc surfacing (EAS) on the working surfaces of parts and mechanisms operating under conditions of intense wear is an effective method of their service life increasing. Surfacing, as a method of protecting parts and tools operating under conditions of abrasive, shock-abrasive wear, has been used for a long time and has become widespread. The EAS method makes it possible to obtain wear-resistant coatings and has a high productivity. The mass of the metal applied to the part during the surfacing process is usually small and amounts to $2-6 \%$ of the mass of the part itself, which determines the high surfacing efficiency. As a result of EAS, it is possible to form a coating with a strong bond with the substrate and the absence of porosity [1-4].

Traditionally, stellites, sormite and many other materials are used for surfacing electrodes, which are significantly inferior in properties to hard alloys. Also used are flux-cored electrodes and wires filled with charge of various compositions. Such electrodes have significant disadvantages in comparison with compact ones: complexity in manufacturing, high specific energy required for surfacing, inconvenience in operation. To obtain these electrodes, powder metallurgy techniques are used: pressing and vacuum sintering or hot pressing. These technologies involve a large number of operations, many of which are complex, energy intensive and time consuming. After using their technological functions, plasticizing substances are not completely removed during sintering and affect the physical and mechanical properties of electrode materials. As a rule, not all deposited materials have the required level of physical and mechanical properties.

In recent years, the development of highperformance and cheap methods of obtaining coatings on the surface of tools and technological equipment based on metal-matrix composites (MMC) based on titanium alloys has been underway. One of the most promising hardeners is titanium monoboride, which has a high Young's modulus, high strength, and a close value of the coefficient of thermal expansion. Titanium monoboride is chemically inert with respect to the matrix of the metal binder [5-7]. In turn, titanium 
diboride is characterized by high hardness, wear resistance, heat resistance and heat resistance. Thus, materials with a complex structure of monoboride, diboride, and a metal bond, in various mass ratios, are used as hard heat-resistant and wear-resistant coatings for products for various purposes. Such composites combine the ductility and toughness of a titanium matrix with high strength, hardness, rigidity, and heat resistance. Today, there is a constant increase in the share of ceramic alloys and composite materials based on titanium borides in rocketry, aircraft structures, the automotive industry, as biological implants, and also as hard heat-resistant coatings for products for various purposes [8-11].

The problem of an industrial method of producing surfacing electrodes based on MMC has not been solved. The introduction of progressive methods of hardening parts and tools for various purposes by electric arc surfacing is hampered by the lack of a sufficient number of these electrodes.

Promising methods for producing products from these materials include the energy-efficient and resource-saving SHS extrusion method for the direct production of long-length products in one technological stage as a result of a combination of combustion processes and high-temperature shear deformation of synthesis products, namely SHS extrusion [12]. This method avoids the need for external heating and long holding by using the internal energy of the reacting system released during the chemical reaction. Since SHS is characterized by high reaction temperatures (over $2000^{\circ} \mathrm{C}$ ) [13], the synthesized products are in a plastic state. The main advantages of the SHS extrusion method are the simplicity of the manufacture of electrodes and the high content of the wear-resistant component in them, the proportion of which can reach 80 mass. \%. This method makes it possible to obtain long compact products with a residual porosity of no more than $5 \%$ in one technological stage in tens of seconds. The mechanisms of phase and structure formation in electrodes obtained under SHS-extrusion conditions and in surfacing coatings deposited by these electrodes poses new problems in the field of theory and practice of this direction of research, which is important for practical application.

The purpose of this work is to obtain protective coatings by electric arc surfacing of SHS electrodes based on titanium borides in an inert argon atmosphere; study of the phase composition, structure and properties of SHS electrodes and surfacing coatings obtained by these electrodes.

\section{Experimental technique}

Electric arc surfacing of composite coatings was carried out in an inert atmosphere of argon at an arc current of $80 \mathrm{~A}$. To create an arc, a non-consumable tungsten electrode was used, as an additive - SHS electrodes based on titanium boride of the composition TiB-30 wt. \% Ti with a diameter of $3 \mathrm{~mm}$. A VT1-0 plate $2 \mathrm{~mm}$ thick served as a substrate.

In order to obtain SHS electrodes, titanium and boron powders were mixed in an equimolar ratio to form titanium monoboride by the chemical reaction $\mathrm{Ti}+\mathrm{B} \rightarrow \mathrm{TiB}$ with the addition of $30 \% \mathrm{Ti}$ as a binder. The presence of the titanium binder provided the required level of plasticity of the material for its extrusion after the reaction of titanium monoboride synthesis. The resulting powder mixture was subjected to pressing and subsequent SHS extrusion.

A detailed analysis of the structure of the crosssection of the SHS electrode and surfacing coatings was carried out by scanning electron microscopy (SEM) on an ultrahigh-resolution field emission scanning electron microscope Zeiss Ultra plus based on Ultra 55 (Germany).

X-ray phase analysis (XRD) was carried out on an ARL X'TRA X-ray diffractometer (Thermo Fisher Scientific, Switzerland). To analyze the phase composition of the surfacing coating, powder samples were prepared.

Microhardness was measured using a PMT-3 microhardness meter.

\section{Results and discussion}

According to the results of the X-ray diffraction (XRD) (Fig. 1) and scanning electron microscopy (SEM) (Fig. 2), the structure of the filler SHS electrode is represented by solid inclusions of titanium monoboride $\mathrm{TiB}$, uniformly distributed in the titanium matrix. Boride particles have a whisker morphology. The matrix is a solid solution of boron in titanium Ti[B $]_{x}$. At the periphery (Fig. $2 a$ ), due to the stresses arising during extrusion of the material, they are located along the direction of extrusion; when approaching the center (Fig. 2b), their co-directionality decreases. Since the cooling of the core proceeds at a slower rate than at the edges, larger particles of titanium monoboride are observed in the center. The average size of the whiskers is $5-10 \mu \mathrm{m}$ in length and $1-4 \mu \mathrm{m}$ in width.

Fig. 3 shows a transverse sectionphotograph of the deposited specimen. The thickness of the deposited layer is $2.5 \mathrm{~mm}$. It should be noted that the fusion line is continuous at the boundary between the coating and the titanium substrate, which indicates a high adhesive strength. 


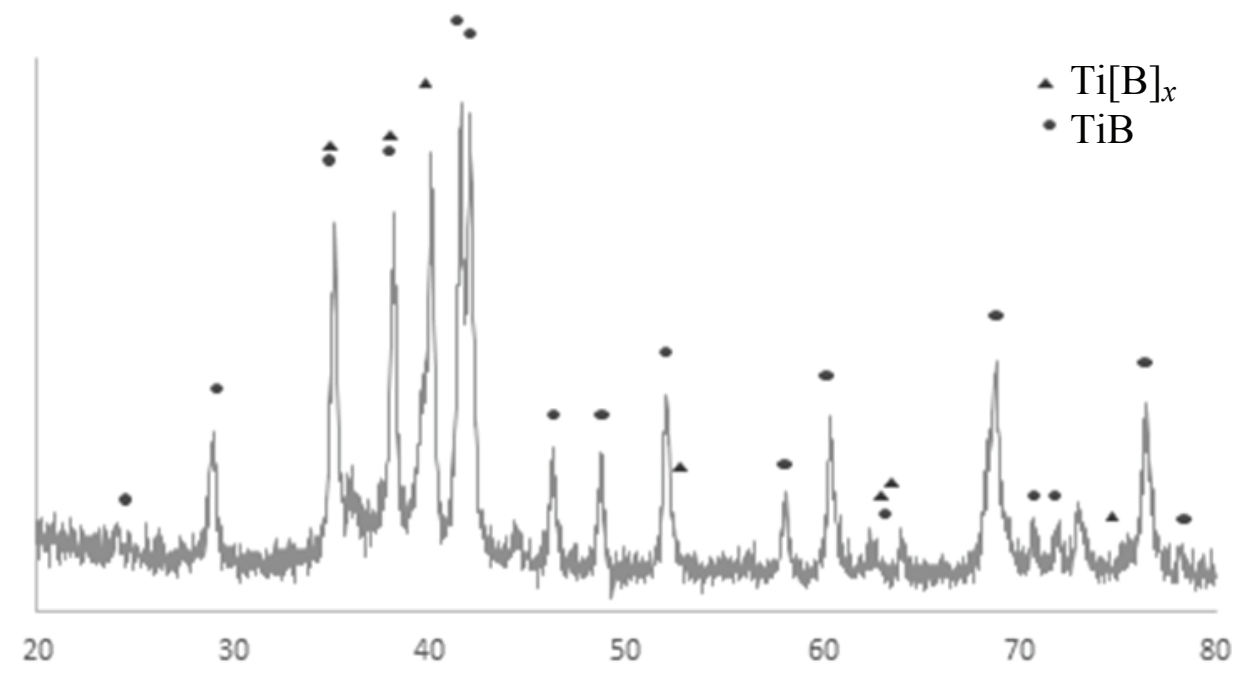

Fig. 1. X-ray diffraction pattern of the SHS electrode

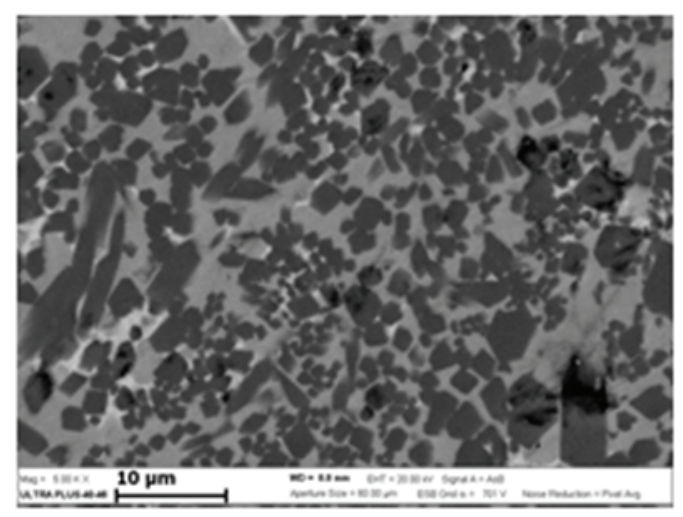

a)

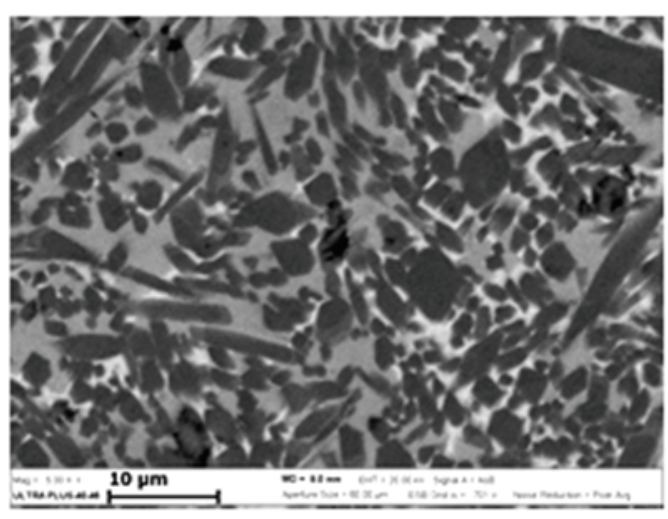

b)

Fig. 2. Transverse section microstructure of a SHS surfacing electrode based on titanium monoboride TiB at the periphery $(a)$ and in the center $(b)$

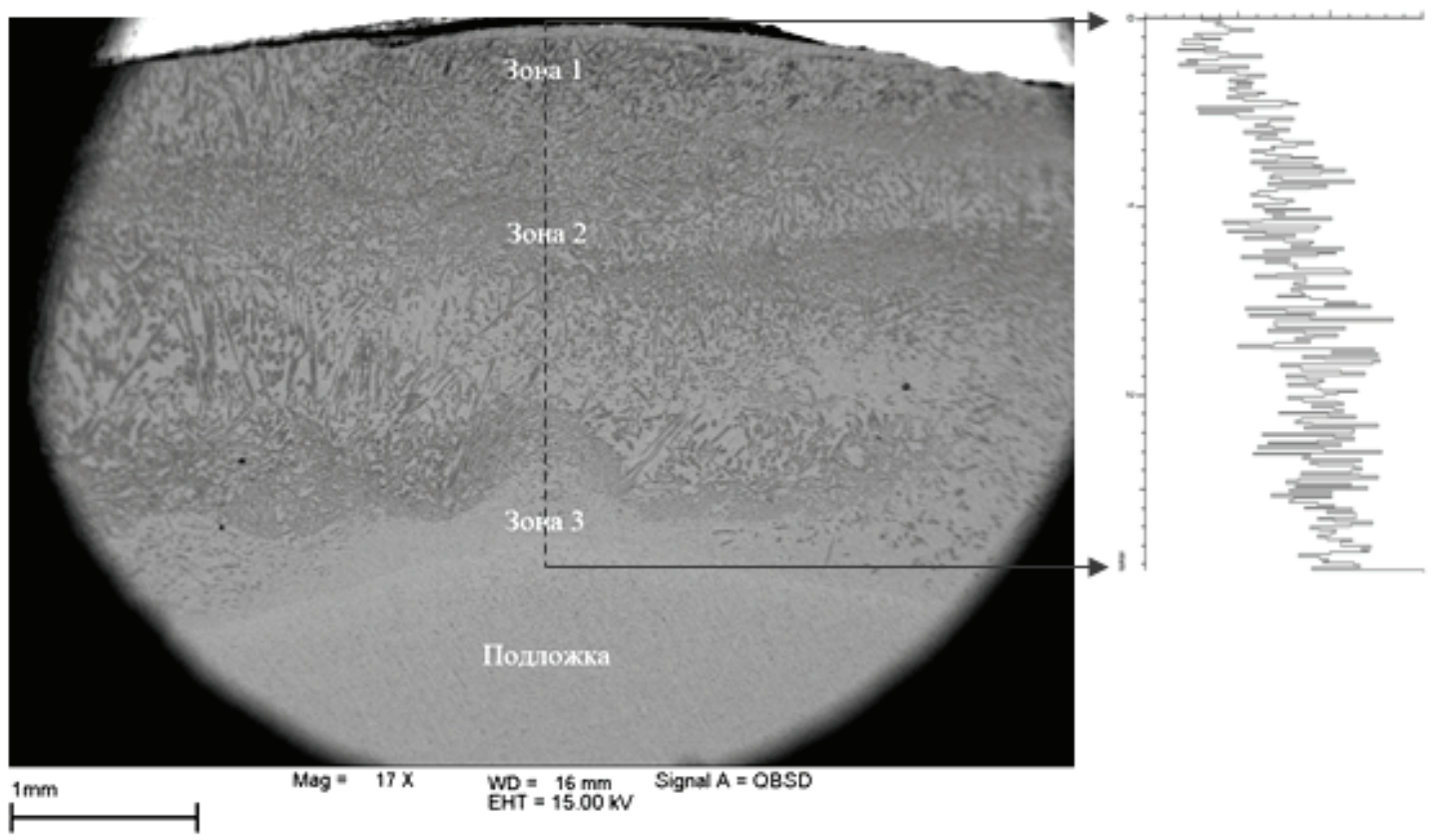

Fig. 3. Cross section and titanium distribution curve in the cross section of the deposited sample 


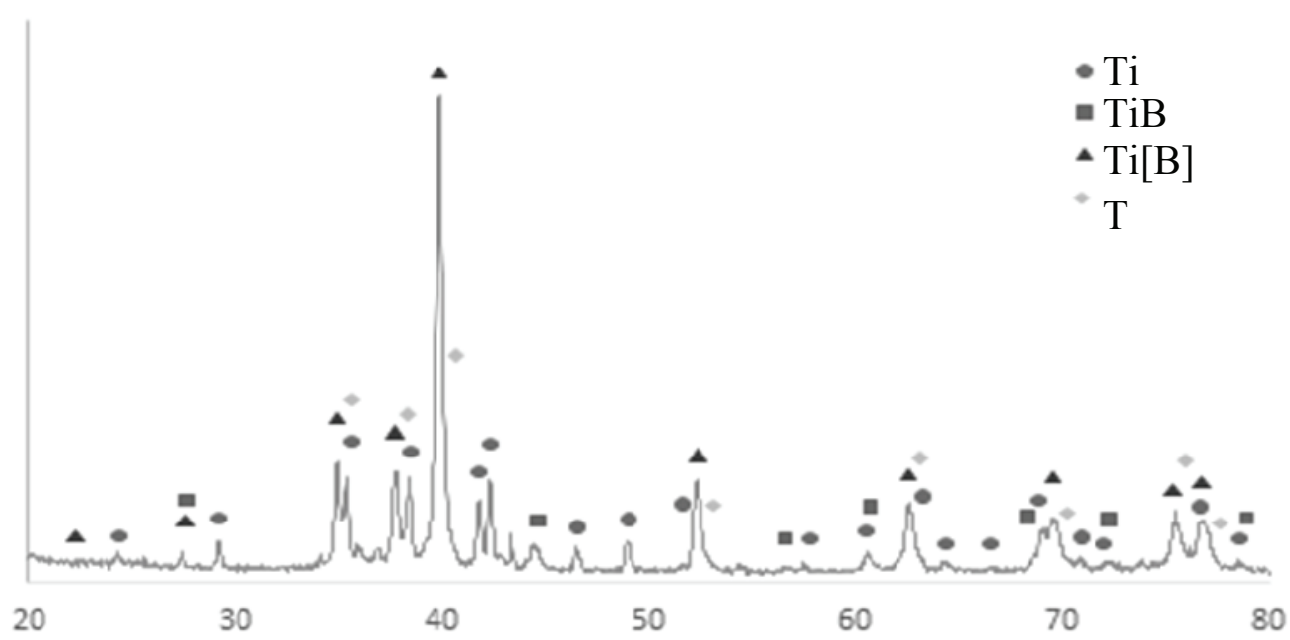

Fig. 4. X-ray diffraction pattern of the deposited coating

The microstructure of the deposited coating is qualitatively similar to the microstructure of the used filler SHS electrodes. According to the XRD results (Fig. 4), it is represented by solid particles of titanium borides $\left(\mathrm{TiB}\right.$ and $\left.\mathrm{TiB}_{2}\right)$ in the form of whiskers located in the $\mathrm{Ti}[\mathrm{B}]_{x}$ solid solution matrix. The growth of whiskers as a result of surfacing cooling occurs predominantly along the longitudinal axis of the specimen, which is associated with directed heat removal into the substrate, with the formation of a columnar structure. The maximum size of boride particles in the deposited layer reaches $500 \mu \mathrm{m}$ in length. Titanium diboride presumably could appear in the coating as a result of enrichment of titanium monoboride with boron from a solid solution. The presence of free titanium in small proportions in the coating may be due to the fact that during surfacing a so-called weld pool is formed, in which the molten material of the surfacing electrode and the substrate material are continuously mixed until it solidifies. The titanium content in the deposited specimen changes over its cross section, which is also shown in Fig. 3, as it approaches the substrate, it constantly increases.

The surfacing has a layered structure, it can be conditionally divided into zones (Fig. 3): zone 1 - nearsurface layer, zone 2 , zone 3 - transitional diffusion layer. The structure of each zone is shown in Fig. 5.

In the near-surface zone 1 with thickness of $0.3 \mathrm{~mm}$ (Fig. 5a), a boron-enriched layer was formed, in which, in addition to titanium monoboride TiB (gray whiskers), titanium diboride $\mathrm{TiB}_{2}$ (black whiskers) was formed, which is also evidenced by the results of X-ray structural analysis (Fig. 4 ). The average size of the whiskers is $50-70$ microns in length and $7-10$ microns in thickness.

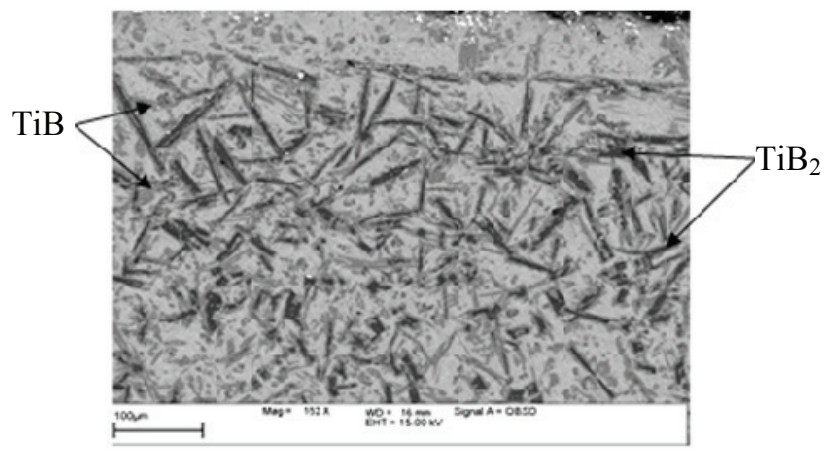

a)

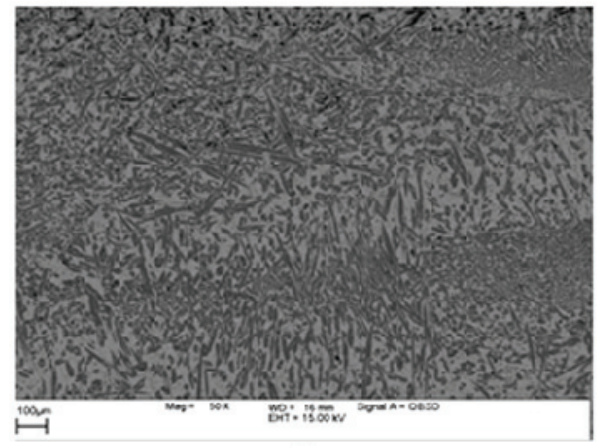

b)

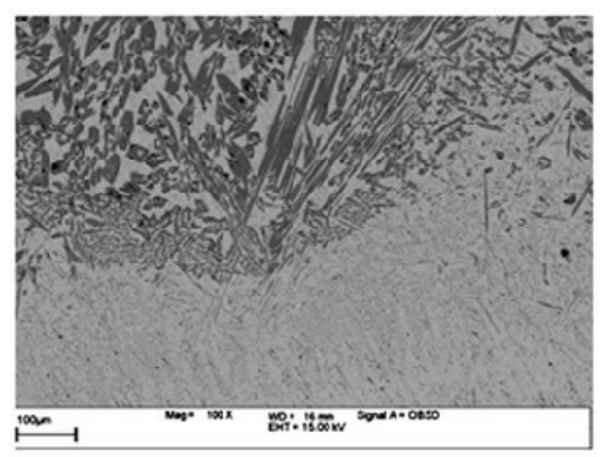

c)

Fig. 5. Coating microstructure of the near-surface zone $1(a)$, zone $2(b)$ and transition zone $3(c)$ 
The structure of zone 2 is identical to the structure of the electrode, however, the size of boride particles is much larger: the average length is $140 \mu \mathrm{m}$ (Fig. 5b), and the average width is $10 \mu \mathrm{m}$.

The formation of a transition zone 3 is due to the mutual diffusion of the molten electrode and substrate material, where elongated and thin $\mathrm{TiB}$ whiskers are formed during crystallization (Fig. $5 c$ ), which in turn can be the centers of crystallization of large titanium monoboride whiskers $(500 \mu \mathrm{m})$ growing in zone 2 towards surfacing layers. The thickness of the transition zone can be estimated to be approximately $0.5 \mathrm{~mm}$. Its presence between the deposited composite layer and the substrate indicates high adhesion of the coating to the substrate.

The microhardness of the deposited electrode and coating was 1024 and $1420 \mathrm{HV}$, respectively.

\section{Conclusions}

1. Technological modes (electric arc current, arc speed, argon flow intensity, etc.) have been worked out for the protective coatings application with electrodes obtained by SHS extrusion by the electric arc surfacing method in an argon atmosphere.

2. It has been established that the coating structure has a pronounced layered character, where 3 zones can be distinguished:

- near-surface zone. A distinctive feature of this zone is the formation of titanium diboride $\mathrm{TiB}_{2}$ in the form of whiskers, along with whiskers of titanium monoboride $\mathrm{TiB}$ in a matrix that is boron solid solution in titanium and titanium. The surface layer of the coating has an increased hardness of $1420 \mathrm{HV}$ while maintaining the adhesion strength with the underlying layers;

- second zone. The structure and phase composition of this zone are identical to the structure and phase composition of the used SHS electrode: titanium monoboride whiskers are uniformly distributed in the titanium matrix;

- transitional (third) zone. This zone is represented by a diffusion layer that differs in structure from zone 2 by the presence of fine boride particles.

The average size of boride particles is: in zone $1-$ length $50-70 \mu \mathrm{m}$ and thickness $5-10 \mu \mathrm{m}$, in zone 2 , the length increases to $140 \mu \mathrm{m}$, in zone 3 - fine particles, which makes it difficult to estimate their size at a given resolution of the obtained SEM images.

3. The primary results obtained in this work give grounds to believe that the coatings deposited by EDN with composite ceramic SHS electrodes based on titanium boride can be promising for increasing the wear resistance of cutting and stamping tools, medical tools, parts of agricultural machinery operating in corrosive environments and at elevated temperatures.
The study was supported by the Russian Foundation for Basic Research within the framework of scientific project No. 19-38-90048.

\section{References}

1. Korobov Yu.S., Izoitko V.M., Pryadko A.S., Lukanin V.L. Vosstanovleniye detaley metodom aktivirovannoy dugovoy metallizatsii [Restoration of parts by the method of activated arc metallization]. Avtomobil'naya promyshlennost', 2000, 3, 23-24. (Rus)

2. Bao Y., Huang L.J., An Q., Jiang S., Zhang R., Geng L., Ma Xinxin. Metal transfer and microstructure evolution during wire-feed deposition of $\mathrm{TiB} / \mathrm{Ti}$ composite coating. Journal of materials processing technology, 2019, 274, 116298. doi: 10.1016/ j.jmatprotec.2019.116298

3. Yazdi R., Kashani-Bozorg S.F. Microstructure and wear of in-situ Ti/(TiN plus TiB) hybrid composite layers produced using liquid phase process. Materials chemistry and physics, 2015, 152, 147-157. doi: 10.1016/j.matchemphys.2014.12.026

4. He Y.N., Montgomery C., Beuth J., Webler B. Melt pool geometry and microstructure of Ti6Al4V with B additions processed by selective laser melting additive manufacturing. Materials \& design, 2019, 183, 108-126. doi: 10.1016/j.matdes. 2019.108126

5. Hayat M.D., Singh H., He Z., Cao P. Titanium metal matrix composites: An overview. Composites part a-applied science and manufacturing, 2019, 121, 418-438. doi: 10.1016/j.compositesa. 2019.04.005

6. Nasakina E.O., Sudarchikova M.A., Demin K.Yu., Gol'dberg M.A., Baskakova M.I., Tsareva A.M., Ustinova Yu.N., Leonova Yu.O., Sevost'Yanov M.A. The effect of the titanium surface layer thickness on the characteristics of a layered composite material. Journal of Physics: Conference Series, 2019, 012057.

7. Huang Liqing, Qian Ma, Liu Zuming. In situ preparation of $\mathrm{TiB}$ nanowires for high-performance $\mathrm{Ti}$ metal matrix nanocomposites. Journal of Alloys and Compounds, 2017, 735, 2640-2645. doi: 10.1016/j.jallcom.2017.11.238

8. Zhang L.C., Attar H. Selective Laser Melting of Titanium Alloys and Titanium Matrix Composites for Biomedical Applications: A Review. Advanced engineering materials, 2016, 18(4), 463-475. doi: 10.1002/adem.201500419

9. Hao Y.L., Li S.J., Yang R. Biomedical titanium alloys and their additive manufacturing. Rare metals, 2016, 35(9), 661-671. doi: 10.1007/s12598-016-0793-5

10. Ding H.Y., Zhou G.H., Liu T., Xia M.J., Wang X.M. Biotribological properties of Ti/TiB2 multilayers in simulated body solution. Tribology International, 2015, 89, 62-6.

11. Li H.L., Jia D.C., Yang Z.H., Zhou Y. Achieving near equiaxed alpha-Ti grains and significantly improved plasticity via heat treatment of $\mathrm{TiB}$ reinforced titanium matrix composite manufactured by selective laser melting. Journal of alloys and compounds, 2020, 836, 155344. doi: 10.1016/j.jallcom.2020.155344

12. Stolin A.M., Bazhin P.M.. Manufacture of Multipurpose Composite and Ceramic Materials in the Combustion Regime and High-temperature Deformation (SHS Extrusion). Theoretical Foundations of Chemical Engineering, 2014, 48(6), 751-763. doi: 10.1134/S0040579514060104

13. Bazhin P.M., Stolin A.M., Alymov M.I. Preparation of Nanostructured Composite Ceramic Materials and Products under Conditions of a Combination of Combustion and High-temperature Deformation (SHS Extrusion). Nanotechnologies in Russia, 2014, 9(11-12), 583-600. 